\title{
Differences in the reliance on cuticular hydrocarbons as sexual signaling and species discrimination cues in parasitoid wasps
}

\author{
Jan Buellesbach ${ }^{1,4,5^{*}+}$ D, Sebastian G. Vetter $r^{2,4+}$ and Thomas Schmitt $3,4,5$
}

\begin{abstract}
Background: Cuticular hydrocarbons $(\mathrm{CHC})$ have been documented to play crucial roles as species- and sexspecific cues in the chemical communication systems of a wide variety of insects. However, whether they are sufficient by themselves as the sole cue triggering sexual behavior as well as preference of con- over heterospecific mating partners is rarely assessed. We conducted behavioral assays in three representative species of parasitoid wasps (Hymenoptera: Pteromalidae) to determine their reliance on $\mathrm{CHC}$ as species-specific sexual signaling cues.

Results: We found a surprising degree of either unspecific or insufficient sexual signaling when $\mathrm{CHC}$ are singled out as recognition cues. Most strikingly, the cosmopolitan species Nasonia vitripennis, expected to experience enhanced selection pressure to discriminate against other co-occurring parasitoids, did not discriminate against $\mathrm{CHC}$ of a partially sympatric species from another genus, Trichomalopsis sarcophagae. Focusing on the latter species, in turn, it became apparent that $\mathrm{CHC}$ are even insufficient as the sole cue triggering conspecific sexual behavior, hinting at the requirement of additional, synergistic sexual cues particularly important in this species. Finally, in the phylogenetically and chemically most divergent species Muscidifurax uniraptor, we intriguingly found both CHC-based sexual signaling as well as species discrimination behavior intact although this species is naturally parthenogenetic with sexual reproduction only occurring under laboratory conditions.

Conclusions: Our findings implicate a discrepancy in the reliance on and specificity of CHC as sexual cues in our tested parasitioid wasps. CHC profiles were not sufficient for unambiguous discrimination and preference behavior, as demonstrated by clear cross-attraction between some of our tested wasp genera. Moreover, we could show that only in T. sarcophagae, additional behavioral cues need to be present for triggering natural mating behavior, hinting at an interesting shift in signaling hierarchy in this particular species. This demonstrates the importance of integrating multiple, potentially complementary signaling modalities in future studies for a better understanding of their individual contributions to natural sexual communication behavior.
\end{abstract}

Keywords: Chemical communication, Assortative mating, Mate recognition, Prezygotic reproductive isolation, Speciation, Nasonia, Trichomalopsis, Muscidifurax, Pteromalidae, Hymenoptera

\footnotetext{
* Correspondence: jan.b@berkeley.edu

${ }^{\dagger}$ Equal contributors

'Department of Science, Policy, \& Management, University of California, 130

Mulford Hall, Berkeley, CA 94720-3114, USA

${ }^{4}$ Department of Evolutionary Biology and Animal Ecology, Faculty of Biology,

University of Freiburg, Hauptstr. 1, D-79104 Freiburg, Germany

Full list of author information is available at the end of the article
}

(c) The Author(s). 2018 Open Access This article is distributed under the terms of the Creative Commons Attribution 4.0 International License (http://creativecommons.org/licenses/by/4.0/), which permits unrestricted use, distribution, and reproduction in any medium, provided you give appropriate credit to the original author(s) and the source, provide a link to the Creative Commons license, and indicate if changes were made. The Creative Commons Public Domain Dedication waiver (http://creativecommons.org/publicdomain/zero/1.0/) applies to the data made available in this article, unless otherwise stated. 


\section{Background}

The reliance on sexual cues and signals for successful reproduction has been documented in a wide variety of animal species [1]. Any cues capable of accurately conveying information about species, sex, and reproductive status have the potential to contribute to finding, attracting, securing, and eventually reproducing with suitable mates $[2,3]$. For closely related species occurring in sympatry, sexual signals with high degrees of similarity bear the risk of cross-attraction, which might in turn lead to fitness reductions due to heterospecific attraction, courtship, and mating. This has led to the assumption of increased diverging selection acting on sexual cues and signals and their corresponding recognition mechanisms in sympatric species, reducing the risk of cross-attraction $[4,5]$ and contributing to prezygotic reproductive isolation [6-9].

Insects, the most diverse animal class [10], have been documented to utilize chemical signaling as their predominant mode of communication $[11,12]$. Cuticular hydrocarbons $(\mathrm{CHC})$, the dominant fraction of the waxy lipid layer located on the insects' epicuticle, constitute a particularly versatile group of semiochemicals being involved in a wide variety of signaling systems. Most prominently, $\mathrm{CHC}$ have been documented to play pivotal roles in sexual communication as sex attractants [13-15], and species recognition cues [16-18]. For instance, in closely related species of the Coleopteran families Cerambycidae [19], Lampyridae [20] and Chrysomelidae [21-23], preference of con- over heterospecific mating partners appears to be mediated by species-specific CHC differences. Similarly, crosses between the Lepidopteran species Danaus erippus and Danaus plexippus hint at $\mathrm{CHC}$-mediated prezygotic reproductive isolation [24]. CHC involvement in species recognition and sexual signaling has further been demonstrated in the Hymenopteran wasp families Bethylidae [25] and Braconidae [26].

However, most studies on CHC-based sexual signaling mechanisms have been conducted in the fruit fly genus Drosophila [27-29]. For different Drosophila species, CHC profiles appear to be either sexually monomorphic or dimorphic [30]. In dimorphic species like D. melanogaster, qualitative and quantitative differences between males and females clearly separate their $\mathrm{CHC}$ profiles [30, 31]. It has been demonstrated that this distinction between sexually mono- and dimorphic $\mathrm{CHC}$ profiles contributes to the prevention of cross-attraction between these species [32-34]. Furthermore, it has been demonstrated between different Drosophila species that $\mathrm{CHC}$-mediated mate discrimination and species recognition appear to be more pronounced in sympatric than in allopatric species [35-37]. These examples strongly suggest a distinctive role for $\mathrm{CHC}$-based sexual signaling in prezygotic reproductive isolation between different Drosophila species. However, expanding the knowledge gained from Drosophila to other insect taxa will be indispensable for achieving a more holistic view on the various aspects of $\mathrm{CHC}$-based sexual communication and its influence on reproductive isolation between sympatric species [38].

Recent advances have been made in deciphering $\mathrm{CHC}$ based sexual signaling mechanisms in the jewel wasp species complex Nasonia (Hymenoptera: Pteromalidae), a well-established insect model system providing a unique set of features such as haplodiploidy, cross-fertility of its four species and sequenced genomes [39-41]. Concerning CHC signaling in Nasonia, it has been shown that female $\mathrm{CHC}$ extracts constitute sexual cues capable of eliciting male courtship behaviour in its most prominent and cosmopolitan member, N. vitripennis [42]. Expanding these findings to the whole Nasonia genus and assessing the speciesspecificity of female $\mathrm{CHC}$ cues, we recently discovered that $\mathrm{CHC}$ are distinctive enough to unambiguously characterize sexes and species [43], although the sexual signaling function in female $\mathrm{CHC}$ could not be unambiguously demonstrated for all Nasonia species [43, 44].

The present study attempts to assess the role of $\mathrm{CHC}$ in sexual signaling, their species-specificity and their potential as prezygotic hybridization barriers in a larger phylogenetic context. Nasonia vitripennis was tested together with two other genera of the parasitoid wasp family Pteromalidae, assessing whether $\mathrm{CHC}$ are sufficient as sexual signaling cues for triggering male courtship and copulation behavior, which is only rarely assessed in parallel in CHC signaling studies. Furthermore, we investigated whether males can discriminate con- from heterospecific females based on their $\mathrm{CHC}$ profiles, thus elucidating the degree of speciesspecificity in CHC-mediated sexual signaling to assess their potential function in prezygotic reproductive isolation.

The representative species of Nasonia and its two most closely related genera Trichomalopsis and Muscidifurax [45] chosen for this study were the cosmopolitan $N$. vitripennis, the wide-spread biological pest control agent $T$. sarcophagae $[46,47]$ and the naturally parthenogenetic $M$. uniraptor [48, 49], which regains the capability of producing males under laboratory conditions [50]. These unique and ecologically divergent genera were chosen to represent a broad variety within the Pteromalidae, one of the largest and economically most important families of parasitoid wasps [51, 52].

We hypothesized that pronounced differences in female $\mathrm{CHC}$ profiles and corresponding male perception capabilities would be apparent in genus-specific recognition and discrimination behavior, potentially contributing to prezygotic reproductive isolation. Particularly since all of our test genera potentially encounter each other in nature [53, 54], we further hypothesized that discrimination behavior among them based on $\mathrm{CHC}$ signaling will generally be enhanced to avoid fitness costs associated with heterospecific matings [55]. Accordingly, our behavioral assays were complemented with a comparative analysis between male and 
female $\mathrm{CHC}$ profiles to investigate whether they cluster in sex- and species-specific groups and whether the female $\mathrm{CHC}$ divergence reflects the differences in male $\mathrm{CHC}$ perception and species discrimination.

\section{Methods}

\section{Experimental strains and rearing conditions}

In the behavioral assays and for the chemical analyses we used laboratory strains from Nasonia vitripennis, Trichomalopsis sarcophagae and Muscidifurax uniraptor. For $N$. vitripennis, we used the strain ITA II, originally collected 2006 in Piedmont, Italy, and provided by L.W. Beukeboom, University of Groningen, The Netherlands. The T. sarcophagae strain was ordered from Beneficial Insectary Inc. ${ }^{\odot}$, Redding, Canada, provided by J. Gadau, Arizona State University, USA, and originally collected in 2004 in Alberta, Canada. The M. uniraptor strain originated from individuals collected in 1963 in Aibonito, Puerto Rico [48] and was provided by J.H. Werren, University of Rochester, USA. M. uniraptor constitutes a naturally parthenogenetic species $[48,49]$ that only tends to produce males under laboratory conditions [50], as was the case for our test strain.

All strains were kept in round plastic vials $(97 \mathrm{~mm}$ height $\times 48 \mathrm{~mm}$ diameter) closed with foam plugs. In these plastic vials pupae of the blowfly Calliphora erythrocephala (MEIGEN) were provided as hosts. The strains were kept in an incubator (RUMED, Rubarth Apparate GMBH, Laatzen, Germany) under a constant temperature of $25{ }^{\circ} \mathrm{C}$ and a light/dark cycle of $16 / 8 \mathrm{~h}$. These standardized conditions lead to a generation time of approximately 14 days for wasps from the genus Nasonia [56], whereas T. sarcophagae and $M$. uniraptor showed a generation time of approximately 16 days under these conditions. Wasps were collected from their blowfly hosts in the pupal stage before eclosure and their sex was determined according to the presence or absence of the ovipositor. Male and female pupae were subsequently kept separately in groups of about 20 individuals to ensure their virginity at the beginning of the mating trials. After eclosure, the adult wasps were allowed to mature for $48-72 \mathrm{~h}$ before they were freeze-killed or exposed to a potential mating partner.

\section{Behavioral assays}

All behavioral observations were carried out in a round mating chamber with a diameter of $1 \mathrm{~cm}$ and a height of $0.5 \mathrm{~cm}$ as described by Ruther et al. [57]. Experiments were initiated by simultaneously placing a male and a female wasp into the mating chamber and directly closing the opening with a cover slide. Single observations were carried out for five minutes under a stereomicroscope in 10-fold magnification and under cold light. For establishing the function of female $\mathrm{CHC}$ profiles as mating cues for the males, we first assessed mate acceptance rates of male wasps from all three tested genera by pairing them with differentially treated conspecific females (see below) and recording whether they show both courtship behavior and/or actual copulation attempts. Pteromalid male courtship behavior usually constitutes of mounting a female wasp and displaying a stereotypic sequence of head nods, typically indicating readiness to mate [58-60]. In male M. uniraptor, the head nod sequence is largely replaced by antennal sweeps while mounting the female and this very comparable stereotypical behavior was recorded as courtship for this species instead [61, 62]. For copulations, the male usually stops his courtship display and backs up to inject his penis (aedeagus) into the female's genital opening [60]. The presence or absence of both of these stereotypical and well-characterized behaviors was recorded in all tested combinations.

Males were tested with conspecific females that were either (i) untreated, (ii) freeze-killed, (iii) "cleared" of their CHC profile (i.e., freeze-killed females kept for $24 \mathrm{~h}$ in hexane, effectively removing the whole $\mathrm{CHC}$ profile with minute to non-detectable amounts remaining on the cuticle [43]), and (iv) "cleared" and reconstituted with conspecific female $\mathrm{CHC}$ extract. The $\mathrm{CHC}$ extracts were obtained by placing two freeze-killed females for $10 \mathrm{~min}$ in a

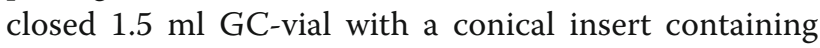
$10 \mu \mathrm{l}$ of hexane. Reconstitution of the $\mathrm{CHC}$ profile was achieved by applying $5 \mu \mathrm{l}$ of the extract (containing one female equivalent) directly after the extraction to conspecific CHC-cleared females [43]. Pre-trials with fractionated cuticle extracts showed that the sexual signaling function is mediated through the nonpolar $\mathrm{CHC}$ hexane fraction, and not through the polar fraction (separated as $\mathrm{CH}_{2} \mathrm{Cl}_{2}$ fraction) [43].

For establishing the species-specificity of female $\mathrm{CHC}$ signaling, we then proceeded to test male species discrimination by comparing courtship and copulatory behavior on con- vs. heterospecific freeze-killed females in all possible species combinations. Freezekilled females were used as opposed to alive ones for two main reasons: First, using freeze-killed females in behavioral trials largely reduces other signaling modalities (e.g., behavioral, acoustic and tactile cues) and augments the importance of chemical cues for correctly identifying a potential mating partner [43, 63]. Second, completely removing or reconstituting $\mathrm{CHC}$ profiles has so far not been possible with alive Pteromalid females (Buellesbach \& Schmitt, unpublished data). This is most probably due to the function of native $\mathrm{CHC}$ profiles as desiccation barrier [64, 65], rendering a complete removal or replacement without leaving traces of the original profile extremely difficult while simultaneously keeping the female alive. 
To accommodate for their generally indifferent behavior towards freeze-killed females, we specifically designed additional assays for $T$. sarcophagae males. These assays were carried out like described above except that untreated (alive) con- and heterospecific females were used. In addition to male courtship behavior and copulation attempts, we also recorded the display of female receptivity in these assays, which is generally signaled by rising their abdomen and thus exposing their genital opening $[60,62]$.

20 replicates were done per treatment, and the number of replicates where males showed courtship behavior or copulation attempts, or, in case of the assays with $T$. sarcophagae males and untreated (alive) females, where females signaled receptivity, were compared independently using $X^{2}$ (Chi)square tests. If the $x^{2}$-square test was positive $(p<0.05)$, onesided proportion tests were done as posthoc statistics. $P$-values from the posthoc tests were corrected for multiple testing by Benjamini-Hochberg corrections with the false discovery rate set to 0.05 [66]. All statistics were carried out with the program $\mathrm{R}$ and the package "stats" ([67], version 2.14.2).

\section{GC-MS analysis of the $\mathrm{CHC}$ profiles}

Seventy nine male and female wasps of all three species were freeze-killed 48-72 h after eclosure and stored separately by sex and species in glass vials at $-20{ }^{\circ} \mathrm{C}$. For $\mathrm{CHC}$ extraction, each wasp was placed for $10 \mathrm{~min}$ into $10 \mu \mathrm{l}$ hexane. Extracts where then transferred to a fresh vial, concentrated by evaporating them with gaseous nitrogen to $\sim 1 \mu \mathrm{l}$, and subsequently injected into a gas chromatograph coupled with a mass spectrometer (GC: 7890A; MS: 5975C; Agilent Technologies, Waldbronn, Germany) operating in electron impact ionisation mode at $70 \mathrm{eV}$ and a source temperature of $230{ }^{\circ} \mathrm{C}$. The entire sample was injected in a split/splitless injector in the splitless mode with an injector temperature of $250{ }^{\circ} \mathrm{C}$. Separation of compounds was performed on a fused silica capillary column (HP-5 ms: $30 \mathrm{~m} ; 0.25 \mathrm{~mm}^{2}$ ID; Agilent Technologies, Waldbronn, Germany) coated with a $0.25 \quad \mu \mathrm{m} \quad$ (5\%-phenyl)-methylpolysiloxane stationary phase with a temperature program starting from $60{ }^{\circ} \mathrm{C}$ and increasing by $40{ }^{\circ} \mathrm{C}$ per min to $200{ }^{\circ} \mathrm{C}$, followed by an increase of $5{ }^{\circ} \mathrm{C}$ per min to $320{ }^{\circ} \mathrm{C}$. Peak area integration and calculation as well as the identification of the substances were performed using the data analysis software Enhanced Chemstation G1701AA Version A.03.00 (Hewlett-Packard Company, Palo Alto, CA 94304 USA). CHC compounds were identified based on their retention indices and respective mass spectra, where possible [68] and expanded upon from previously reported $\mathrm{CHC}$ compositions in Nasonia, Trichomalopsis and Muscidifurax [42, 43, 53].

To make the Peak areas comparable between the species and sexes, to highlight the relative peak area differences and to correct for size-dependent variation, the peak areas were standardized by geometric means, based on the following formula:

$$
S_{i, j}=\frac{P_{i, j}}{\sqrt[n]{\prod_{j=1}^{n} P_{j}}}
$$

with $S_{i, j}$ referring to the standardized Peak area i of individual $j, P_{i, j}$ to the absolute Peak area $i$ of individual $j$ and $\sqrt[n]{ } \cap P_{j}$ to the geometric mean of all absolute Peak areas of individual $j$. Linear discriminant analysis (LDA) was performed utilizing the R package "MASS" [69] to test whether the differences in relative amounts of the $\mathrm{CHC}$ compounds sufficiently discriminate the six pre-defined groups into the three respective species and two sexes. To measure the quality of the LDA, Wilk's $\lambda, x^{2}$ and the significance level of differentiation according to sex and species were calculated. To visualize the data by plotting the first three discriminant functions simultaneously, the $R$ package "scatterplot3d" was used [70].

\section{Results}

Behavioral assays

In the pairings of $N$. vitripennis males with differentially treated conspecific females, both courtship behavior $\left(\mathrm{CB}: \mathrm{X}^{2}=1.07, P=0.18\right)$ and copulation attempts (CA: $\left.X^{2}=0, P=0.5\right)$ were not significantly different between untreated (alive) and freeze-killed females (Fig. 1a).

However, when freeze-killed females were cleared of their $\mathrm{CHC}$ profiles, male courtship behavior and copulation attempts were significantly reduced compared to pairings with untreated $\left(C B: X^{2}=20.05, P<0.001\right.$; $C A$ : $\left.X^{2}=28.9, P<0.001\right)$ and freeze-killed females $\left(C B: X^{2}=11.4\right.$, $P=0.001$; CA: $\chi^{2}=25.66, P<0.001$ ), respectively (Fig. 1a). Reconstituting the $\mathrm{CHC}$ profiles of previously $\mathrm{CHC}$-cleared females resulted in a significant increase in male courtship behavior (CB: $\left.X^{2}=6.53, P=0.011\right)$ and copulation attempts (CA: $\left.X^{2}=9.64, \quad P=0.002\right)$ compared to CHC-cleared females, restoring courtship to levels not significantly different from freeze-killed females $\left(\mathrm{CB}: \chi^{2}=0.4, P=0.263\right.$; Fig. 1a). Male copulation attempts on $\mathrm{CHC}$-reconstituted females, on the other hand, while showing a significant increase compared to CHC-cleared females (CA: $\chi^{2}=9.64$, $P=0.002)$, were still significantly lower than with untreated (CA: $\left.X^{2}=6.53, P=0.008\right)$ and freeze-killed females (CA: $X^{2}=4.51, P=0.02$; Fig. 1a).

Similarly, courtship behavior and copulation attempts from $M$. uniraptor males were not significantly different between untreated and freeze-killed females, respectively $\left(\mathrm{CB}: \mathrm{X}^{2}=0.16, P=0.654 ; \mathrm{CA}: \mathrm{X}^{2}=0, P=0.5\right.$, Fig. 1b). Clearance of the $\mathrm{CHC}$ profiles resulted in significantly less courtship behavior and fewer copulation attempts than with both untreated (CB: $\left.X^{2}=10.03, P=0.002 ; \quad C A: X^{2}=14.44, P<0.001\right)$ and 


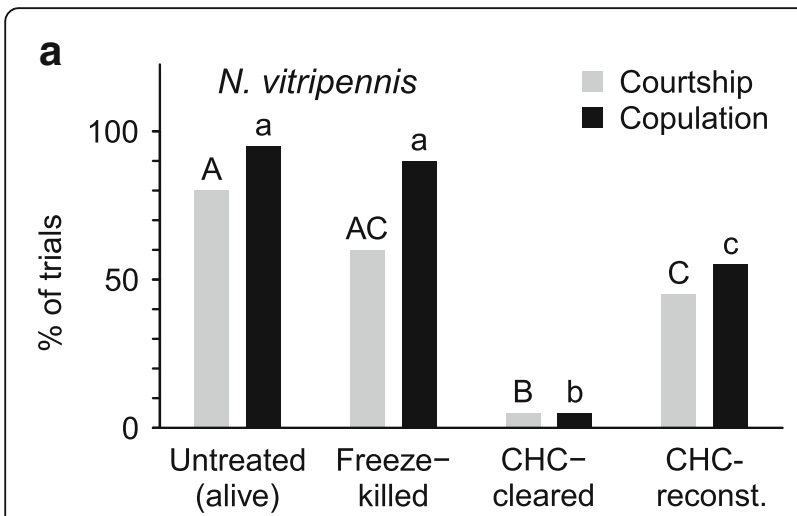

b
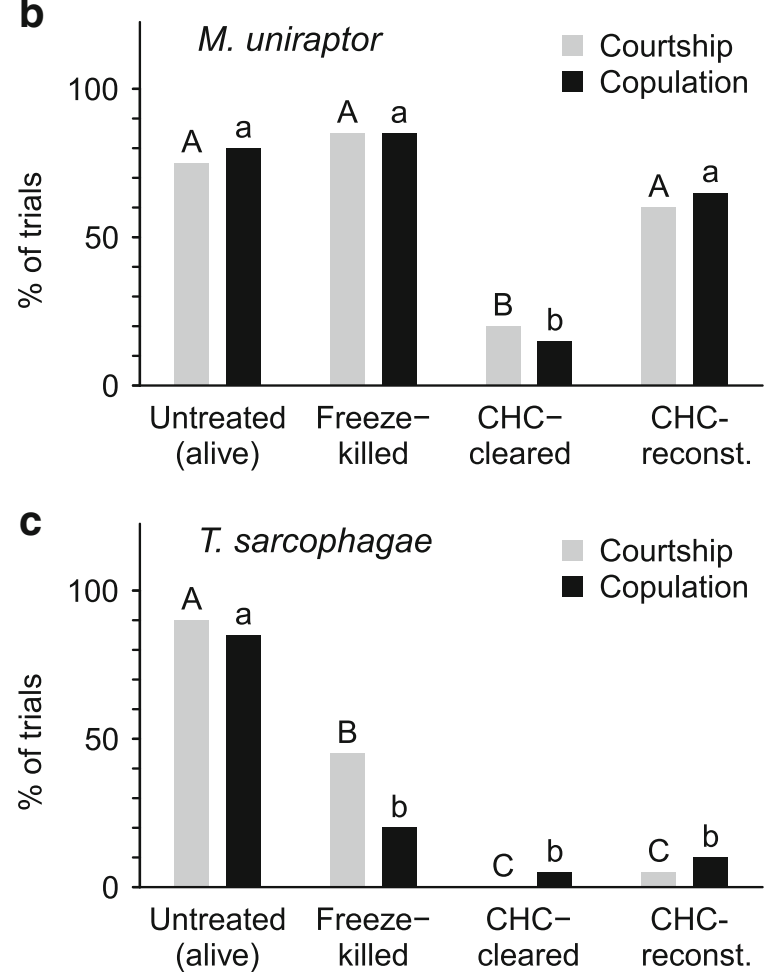

Fig. 1 Percentages of male courtship (light grey bars) and copulation (black bars) with differentially treated conspecific freeze-killed females: a) N. vitripennis; b) M. uniraptor; c) T. sarcophagae. Left to right: Courtship behavior and copulation attempts with untreated (alive) conspecific females, freeze-killed conspecific females, freeze-killed conspecific females with cleared CHC profiles ('CHC-cleared'), and freeze-killed conspecific females with reconstituted $\mathrm{CHC}$ profiles ('CHC'-reconst.). 20 replicates performed for each treatment group, different letters indicate significant differences between treatment groups, upper-case letters are used for courtship behavior, lower-case letters for copulation attempts, compared independently by Benjamini-Hochberg corrected $x^{2}$ (Chi)-square tests, performed on absolute values

freeze-killed females (CB: $X^{2}=14.44, P<0.001$; CA: $\left.X^{2}=16.90, P<0.001\right)$. Reconstituting the $\mathrm{CHC}$ profiles restored both tested behaviors to levels comparable with untreated $\left(\mathrm{CB}: X^{2}=0.46, P=0.3 ; \mathrm{CA}: X^{2}=0.5\right.$, $P=0.287)$ and freeze-killed females (CB: $X^{2}=2.01$, $P=0.118$; CA: $x^{2}=1.2, P=0.205$; Fig. $\left.1 b\right)$.
In contrast, $T$. sarcophagae males showed both significantly less courtship behavior and fewer copulation attempts with freeze-killed than with untreated females (CB: $\chi^{2}=7.29, P=0.005: \mathrm{CA}: \chi^{2}=14.44, P<0.001$; Fig. $1 \mathrm{c}$ ). More strikingly, no difference could be detected in both courtship behavior and copulation attempts between $\mathrm{CHC}$-cleared and $\mathrm{CHC}$-reconstituted females (CB: $\chi^{2}=0, P=0.5 ; \mathrm{CA}: \chi^{2}=0, P=0.5$; Fig. 1c).

In con- vs. heterospecific comparisons (Fig. 2), there was no significant difference when $N$. vitripennis males were paired with conspecific and T. sarcophagae freezekilled females, both in courtship behavior and copulation attempts $\left(\mathrm{CB}: \mathrm{X}^{2}=0, P=0.5\right.$; $\mathrm{CA}: \mathrm{X}^{2}=0.2, P=0.33$, Fig. 2a). In contrast, freeze-killed $M$. uniraptor females were not courted and copulated with at all $\left(\mathrm{CB}: X^{2}=14.4\right.$, $P<0.001$; CA: $X^{2}=29.19, P<0.001$, Fig. 2 a). An additional assay focusing on another $N$. vitripennis population collected in North America in close sympatry with other Pteromalid wasps resulted in a very similar pattern (Additional file 1).

M. uniraptor males both courted and copulated almost exclusively with conspecific freeze-killed females as compared to both heterospecific $N$. vitripennis (CB and CA: $\left.X^{2}=26.19, P<0.001\right)$ and $T$. sarcophagae $(\mathrm{CB}$ and $C A$ : $\left.X^{2}=22.73, P<0.001\right)$ freeze-killed females.

In heterospecific pairings with $T$. sarcophagae males, courtship of freeze-killed $N$. vitripennis females was not significantly different from courtship of conspecifics (CB: $X^{2}=0.99, P=0.16$ ), but significantly lower with freeze-killed $M$. uniraptor females that were not courted at all $\left(C B: X^{2}=9.18, P=0.004\right)$. No significant differences could be detected in copulation attempts of $T$. sarcophagae males with con- and heterospecific freeze-killed females $\left(\mathrm{CA}: \mathrm{X}^{2}=4.44, P=0.108\right.$; Fig. 2c).

When paired with untreated (alive) females, T. sarcophagae males initially showed courtship behavior to the same extent with conspecific and $N$. vitripennis females $\left(\mathrm{CB}: X^{2}=0\right.$, $P=0.5$ ). Female receptivity signaling, however, was significantly lower in the latter, heterospecific pairing (FR: $\chi^{2}=21.85, P<0.001$ ), mirroring significantly fewer copulation attempts (CA: $\left.X^{2}=12.22, P<0.001\right)$. Finally, compared to the conspecific pairing, untreated $M$. uniraptor females were significantly less courted $\left(\mathrm{CB}: X^{2}=22.5, P<0.001\right)$, copulated with $\left(\mathrm{CA}: \chi^{2}=22.73\right.$, $P<0.001$ ), and signaled no receptivity at all (FR: $X^{2}=6.27$, $P=0.009$ ) when paired with $T$. sarcophagae males.

\section{Chemical analysis of the $\mathrm{CHC}$ profiles}

A total of 79 individuals were pre-defined into six groups, constituting the three wasp genera with both respective sexes, for a linear discriminant analysis (LDA) according to their $\mathrm{CHC}$ profile differences (Fig. 4). All profiles were significantly differentiated according to sex and species (Wilk's 


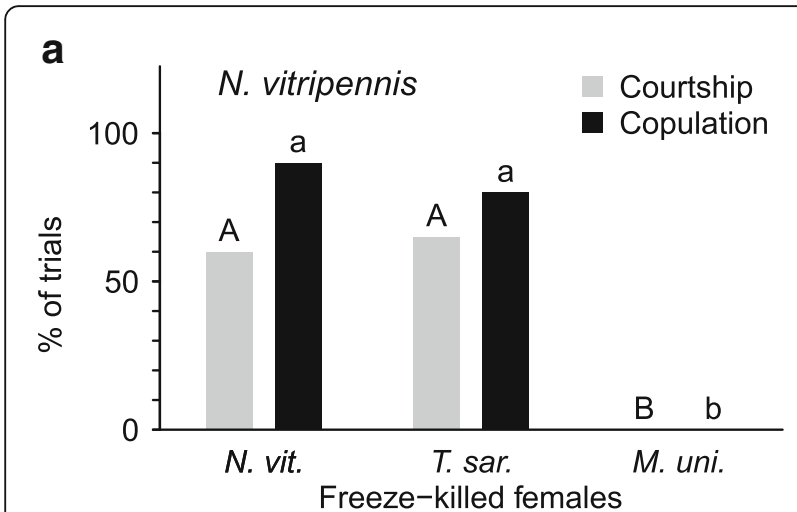

b

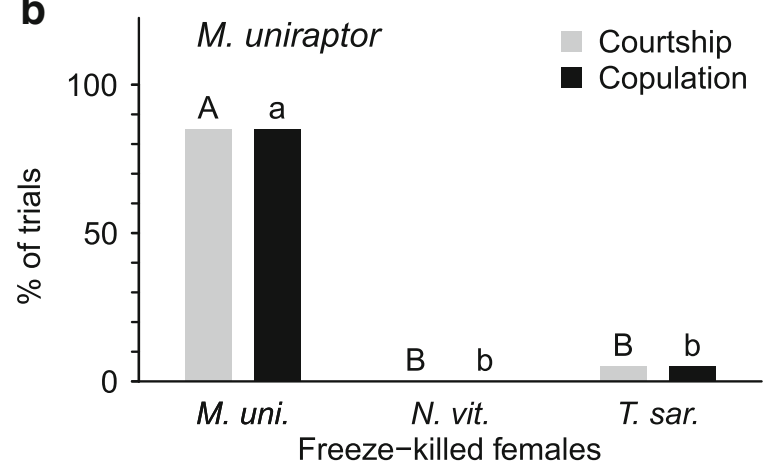

C

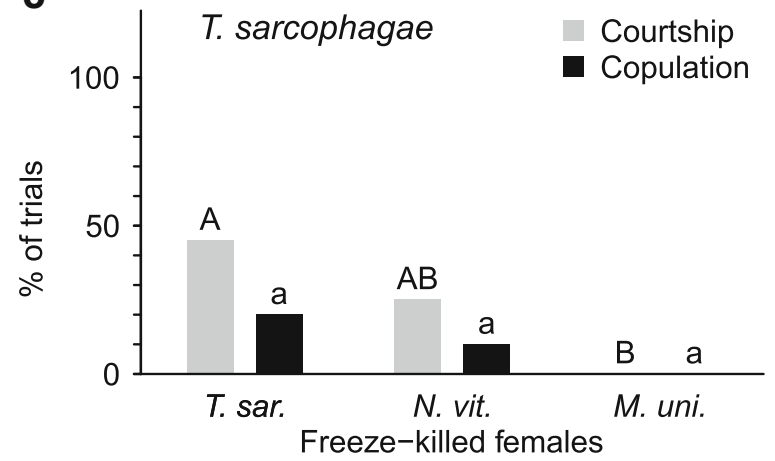

Fig. 2 Percentages of male courtship (light grey bars) and copulation (black bars) with con- and heterospecific freeze-killed females: a) N. vitripennis; b) M. uniraptor; c) T. sarcophagae. Left: Courtship behavior and copulation attempts with conspecific freeze-killed females, respectively paired with the focal male species. Center and right: Courtship behavior and copulation attempts with heterospecific freeze-killed females. 20 replicates performed for each treatment group, different letters indicate significant differences between treatment groups, upper-case letters are used for courtship behavior, lower-case letters for copulation attempts, compared independently by Benjamini-Hochberg corrected $x^{2}$ (Chi)-square tests, performed on absolute values

$\left.\lambda<0.001, \chi^{2}=1199.36, P<0.001\right)$. Discriminant function 1 accounts for $47.7 \%$, function 2 for $30.4 \%$ and function 3 for $10.8 \%$ of the total variation, amounting to $88.9 \%$ of total variance explained by the first three functions. Plotted simultaneously, each group is uniquely defined, and no visual overlap between any of the six groups can be found (Fig. 4). Male $\mathrm{CHC}$ profiles cluster far apart from each other according to their respective species affiliation. $N$. vitripennis and $T$. sarcophagae female $\mathrm{CHC}$ profiles, however, cluster more closely together, whereas $M$. uniraptor female profiles cluster further away from both of them. A detailed description of the identified $\mathrm{CHC}$ compounds and relative $\mathrm{CHC}$ abundances per sex and species that form the basis for the divergent clusters is given in Additional file 2.

\section{Discussion}

Our study aimed at elucidating the reliance on and speciesspecificity of female $\mathrm{CHC}$ profiles as sexual cues in three closely related parasitoid wasp genera. First, we investigated and compared both male courtship behavior and copulation attempts with conspecific untreated (alive) females and differentially treated conspecific freeze-killed females (Fig. 1). With freeze-killed females, other signaling modalities, e.g., behavioral, acoustic and tactile cues, are reduced and kept to a minimum, largely augmenting the reliance on chemical cues $[43,63]$. Both $N$. vitripennis and $M$. uniraptor males displayed significantly less courtship and copulation attempts with freeze-killed females whose $\mathrm{CHC}$ profiles have been cleared than with freeze-killed females whose $\mathrm{CHC}$ profiles have been reconstituted (Fig. 1ab). This confirms female $\mathrm{CHC}$ as the main cues for sexual attraction when other signaling modalities potentially emitted from alive females are not present. However, under the same conditions, $\mathrm{CHC}$ are apparently not sufficient in $T$. sarcophagae for triggering male copulation behavior (Fig. 1c). Reconstitution of $\mathrm{CHC}$ profiles on freeze-killed females did not result in any more courtship or copulation attempts from males as compared to both $\mathrm{CHC}$-cleared and untreated freeze-killed females. Thus, the central role of $\mathrm{CHC}$ as cue for female sexual attractiveness in absence of other potential cues emitted from alive females could not be confirmed here for T. sarcophagae. This opposes both our findings for M. uniraptor and $N$. vitripennis as well as other Nasonia species $[43,63]$. Interestingly, in the phylogenetically most distant genus in this study represented by $M$. uniraptor [45], the female $\mathrm{CHC}$ function as sexual cues appears to be fully intact, a surprising finding as males only occur under laboratory conditions in this naturally parthenogenic species [48-50]. Our results suggest that additional cues, potentially emitted from alive females, are necessary for $T$. sarcophagae males for triggering their natural copulation behavior with the signaling of female receptivity appearing to be the most likely candidate cue (see Fig. 3).

Attempting to assess the species-specificity of this behavior, we also conducted male mate choice assays on con- vs. heterospecific freeze-killed females. Surprisingly, although clearly distinct and chemically different from each other (Fig. 4, Additional file 2), N. vitripennis males 


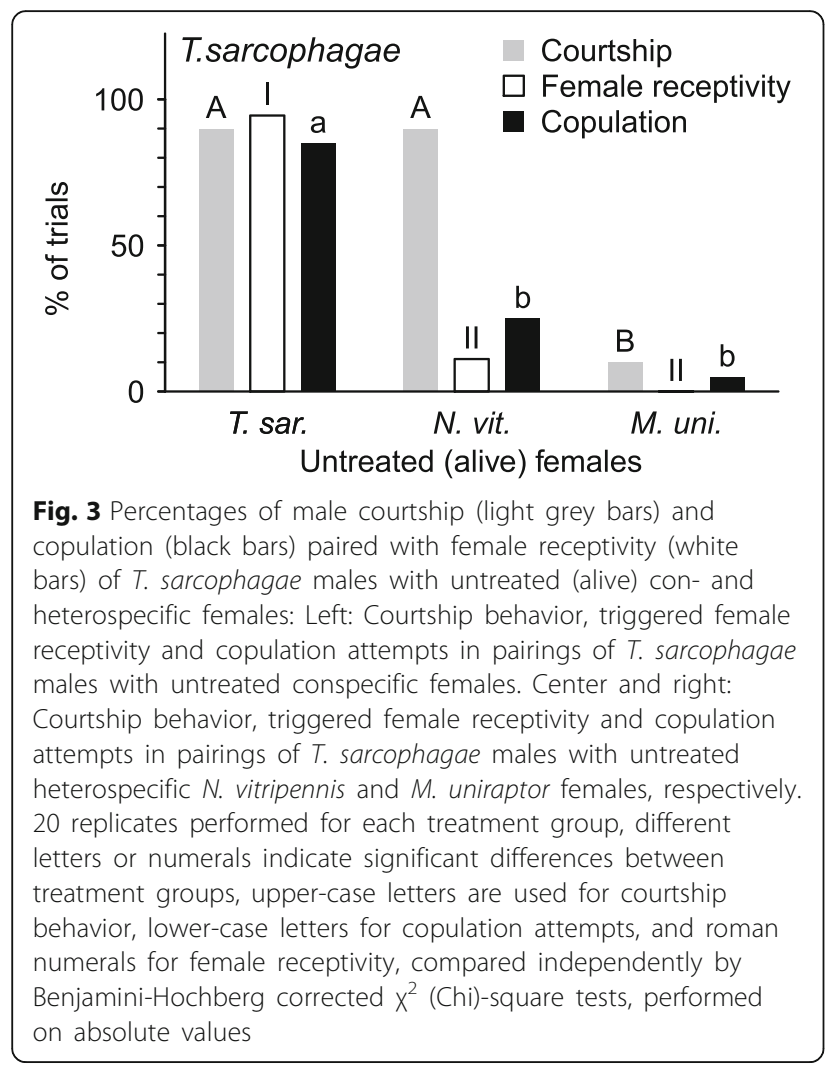

do not discriminate against heterospecific freeze-killed T. sarcophagae females but only against freeze-killed M. uniraptor females (Fig. 2a). As a cosmopolitan species documented to encounter $T$. sarcophagae [54] as well as other Pteromalid species in close sympatry [53, 71, 72], pronounced discrimination behavior would have been expected particularly in $N$. vitripennis. Although acceptance of heterospecific mates has been shown in $N$. vitripennis in behavioral assays with other Nasonia species [44, 63, 73], the extension of this non-selective behavior to a phylogenetically even more distant genus was surprising. Concerning population-specific variation, $N$. vitripennis $\mathrm{CHC}$ profiles have been found to be remarkably stable across populations irrespective of their geographic origin stemming from Europe or North America (Buellesbach, Diao, Beukeboom \& Schmitt., unpublished data). Moreover, males from an $N$. vitripennis population collected in North America also showed non-discriminatory behavior against freeze-killed T. sarcophagae females (Additional file 1), suggesting that $\mathrm{CHC}$ profiles and associated behaviors constitute genetically fixed, species-specific traits with low intraspecific variation, which is also in accordance with studies on other Nasonia species [41, 43, 72].

Theory predicts that discriminatory behavior is generally enhanced in species potentially encountering closely related species in sympatry, especially if postzygotic hybridization barriers inflict fitness costs on interspecific

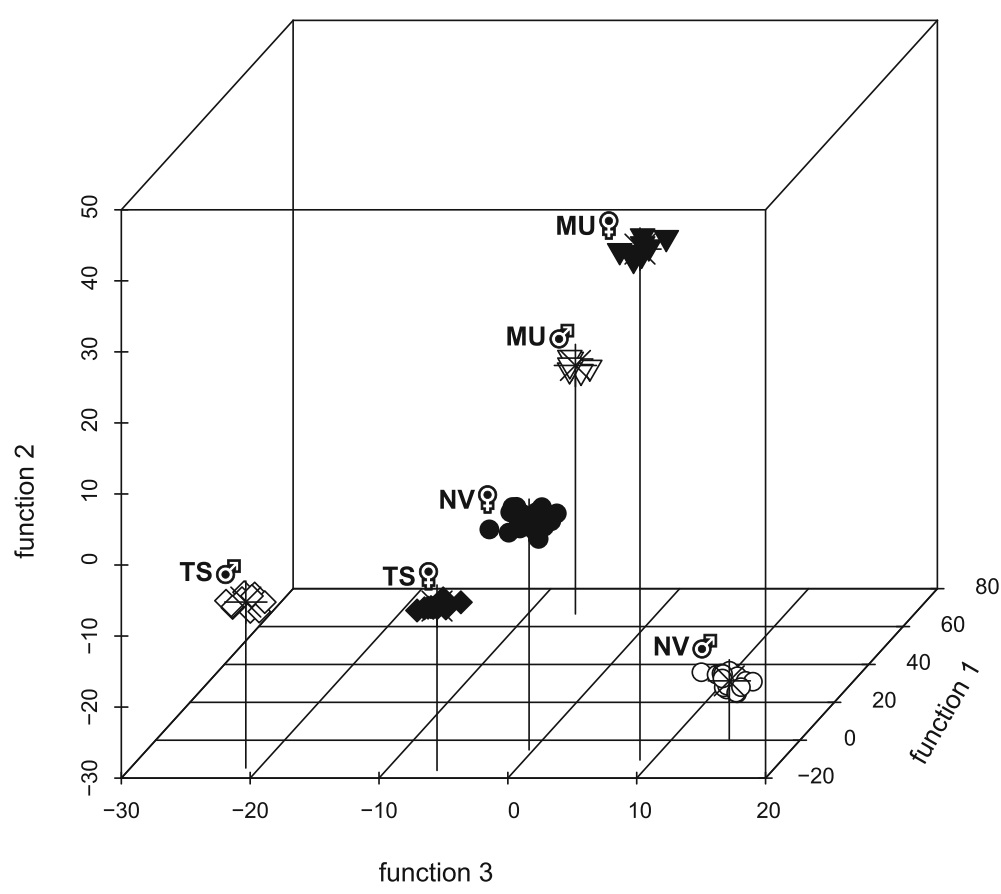

Fig. 4 Three-dimensional linear discriminant analysis (LDA) simultaneously plotting the first three discriminant functions based on the $\mathrm{CHC}$ profile differences of the three tested wasp genera. $\mathrm{NV}=N$. vitripennis, represented by circles, $M U=M$. uniraptor, represented by triangles and $\mathrm{TS}=T$. sarcophagae, represented by diamonds. Males and females are represented by open and closed symbols, respectively, $n=79$ 
reproduction [55, 74, 75]. In the Nasonia genus, postzygotic reproductive isolation mediated by different speciesspecific strains of Wolbachia bacteria leads to a substantial or total reduction of hybrid offspring in interspecific crosses [76-78]. Similarly, lab crosses between $N$. vitripennis and $T$. sarcophagae yielded substantially less hybrid offspring than conspecific control crosses (reduction by more than $60 \%$, Additional file 3), hinting at considerable fitness costs inflicted on heterospecific courtship and copulations between these two species. Moreover, both are gregarious, i.e. multiple individual wasps can emerge from a single host pupa, and display both partially overlapping geographic ranges and shared host preferences [54], strongly suggesting an increased potential for sympatric encounters in nature. Apparently, female $\mathrm{CHC}$ profiles do not appear to be sufficiently distinguishable for $N$. vitripennis males to prevent interspecific courtship and copulations since they elicit both types of mating behaviors even with females from a different genus. These results contrast general assumptions that $\mathrm{CHC}$ can serve as sufficiently distinguishable discriminatory cues contributing to prezygotic reproductive isolation particularly on higher taxonomic levels $[16,79,80]$.

In $T$. sarcophagae where female $\mathrm{CHC}$ do not even appear to sufficiently function as sexual cues when isolated from alive females, different signaling modalities potentially took precedence. Pairing T. sarcophagae males with untreated con- and heterospecific females while simultaneously recording female receptivity signaling interestingly revealed that males did not discriminate between conspecific and $N$. vitripennis females in their initial courtship behavior (Fig. 3). Copulation attempts and female receptivity signaling, however, both occurred significantly more often with con- than with heterospecific females. This clearly suggests that behavioral cues provided by alive females are essential for $T$. sarcophagae males to trigger natural copulation behavior, whereas courtship behavior appears to be similarly unspecific as in $N$. vitripennis males. The main behavioral trigger appears to be the signaling of female receptivity for the males to initiate copulation, which also has been found to be an additional important cue in the general mating behavior in Nasonia $[59,60]$ and other Pteromalid species [81, 82]. However, we cannot exclude the possibility that $T$. sarcophagae males possess the general capability to perceive female $\mathrm{CHC}$ as sexual cues. But, as opposed to our other tested genera and most other Nasonia species [43, 63], they do require additional cues and $\mathrm{CHC}$ are not sufficient when they are isolated.

Intriguingly, a similar inconsistency has been found in populations of the Nasonia species $N$. giraulti, where conspecific female $\mathrm{CHC}$ extracts also do not function as sexual cues when singled out $[43,44]$. Taken the present findings for $T$. sarcophagae into account, $N$. giraulti males from certain populations potentially also require additional cues either not present in $\mathrm{CHC}$ extracts [44] or emitted from alive females for successful recognition and ultimately reproduction with conspecific females. These findings emphasize the potential importance of additional behavioral cues when studying chemical communication and also hint at the necessity for the presence and interaction of various communication modalities to trigger natural mating behavior. Our study suggests that the presence or absence of the reliance on certain communication cues to trigger mating behavior can, in fact, be a species-specific trait that may contribute to prezygotic isolation from other sympatric species and genera.

In $M$. uniraptor, female $\mathrm{CHC}$ apparently have retained their sexual signaling capability, being clearly perceivable and preferred by conspecific males (Figs. 1 and 2b), despite the fact that males are naturally absent in $M$. uniraptor populations. This contradicts the theory that sexual signaling characteristics largely disappear if species have become parthenogenetic over longer periods of time [49, 83]. Moreover, M. uniraptor are not only phylogenetically the most divergent [45], but also in terms of their $\mathrm{CHC}$ profiles (Fig. 4), potentially explaining that no courtship or copulations were recorded at all for $N$. vitripennis (Fig. 2a) and T. sarcophagae (Fig. 2b) males with freezekilled $M$. uniraptor females.

\section{Conclusions}

We found remarkable differences in the reliance on $\mathrm{CHC}$ as both sexual stimulant and species-specific recognition cues in our tested parasitoid wasp genera. The function as female sexual cues in isolation of other stimuli could not be confirmed as a universal $\mathrm{CHC}$ characteristic, nor did $\mathrm{CHC}$ mediate distinctive enough recognition behavior to reliably function as prezygotic hybridization barrier between all tested genera. This strongly suggests that in order to obtain a holistic view on sexual signaling in relation to reproductive isolation, single signaling modalities such as $\mathrm{CHC}$ should be regarded in conjunction with other communication modes rather than isolated [11, 84]. In larger phylogenetic contexts, several different signaling modalities potentially comprise a rather complex, synergistic network ensuring the functionality of species-specific sexual communication, though this has rarely been assessed empirically so far $[21,22,85,86]$.

Future studies should direct more effort into incorporating and integrating these different communication modalities, presumably complementing each other to unfold their full potential as prezygotic hybridization barriers. Overall, interactions of various communication modalities and differences in the reliance on each one of them might be an important factor contributing to the divergence of populations, prezygotic reproductive isolation and, ultimately, speciation $[55,75,87]$. 


\section{Additional files}

Additional file 1: Percentages of male courtship (light grey bars) and copulation (black bars) with con- and heterospecific freeze-killed females tested with males and females from an N. vitripennis population originally collected in 2006 in New York, North America (N.A.). 20 replicates performed for each treatment group, different letters indicate significant differences between treatment groups, upper-case letters are used for courtship behavior, lower-case letters for copulation attempts, compared independently by Benjamini-Hochberg corrected $X^{2}$ (Chi)-square tests, performed on absolute values. (PDF $52 \mathrm{~kb}$ )

Additional file 2: CHC compounds identified from males and females of Nasonia vitripennis, Trichomalopsis sarcophagae, and Muscidifurax uniraptor. Compound identifications, retention indices (RI), and their mean relative abundances (\%) as well as standard deviations ( \pm \%) for each respective sex and species are given. $X$ indicates non-detectable amounts of the respective compounds. (DOCX $30 \mathrm{~kb})$

Additional file 3: F1 male and female offspring from crosses between T. sarcophagae males with conspecific virgin $T$. sarcophagae and heterospecific $N$. vitripennis females, respectively. Note that only female offspring constitutes hybrid offspring as Hymenopteran males develop from haploid, unfertilized eggs. The $N$. vitripennis strain used for the crosses has been antibiotically cured of its Wolbachia infection and was originally collected in Leiden, The Netherlands. (DOCX $13 \mathrm{~kb}$ )

\section{Acknowledgments}

Special thanks to J. Gadau, L.W. Beukeboom and J.H. Werren for providing the lab strains tested in this study, and to J.D. Gibson for valuable suggestions on the first draft of this manuscript.

\section{Funding}

This study was supported in part by the Excellence Initiative of the German Federal and State Governments (GSC-4, Spemann Graduate School).

\section{Availability of data and materials}

All datasets used and/or analyzed during the current study are either included in this published article or available from the corresponding author on reasonable request.

\section{Authors' contributions}

Authors JB and SV contributed equally to this work. TS and JB initiated the study. TS, JB and SV conceived the experiments. SV conducted the experiments and generated the behavioral and chemical data. JB and SV analyzed, interpreted and visualized the data. TS provided material and resources. JB took the lead in writing the manuscript. All authors read and approved the final manuscript.

\section{Ethics approval and consent to participate}

There is no ethics committee overseeing experimental research on Pteromalid wasps. However, all efforts were made to treat the animals as humanely as possible.

\section{Competing interests}

The authors declare that they have no competing interests.

\section{Publisher's Note}

Springer Nature remains neutral with regard to jurisdictional claims in published maps and institutional affiliations.

\footnotetext{
Author details

${ }^{1}$ Department of Science, Policy, \& Management, University of California, 130 Mulford Hall, Berkeley, CA 94720-3114, USA. ${ }^{2}$ Research Institute of Wildlife Ecology, Department of Integrative Biology and Evolution, University of Veterinary Medicine Vienna, Savoyenstr. 1, A-1160 Vienna, Austria. ${ }^{3}$ Department of Animal Ecology and Tropical Biology, University of Würzburg, Am Hubland, D-97074 Würzburg, Germany. ${ }^{4}$ Department of Evolutionary Biology and Animal Ecology, Faculty of Biology, University of Freiburg, Hauptstr. 1, D-79104 Freiburg, Germany. ${ }^{5}$ Spemann Graduate School of Biology and Medicine (SGBM), Albert Ludwigs University Freiburg, Albertstr. 19 A, D-79104 Freiburg, Germany.
}

Received: 31 March 2018 Accepted: 4 April 2018

Published online: 10 May 2018

\section{References}

1. Wyatt TD. Sex pheromones: finding and choosing mates. In: editors. Pheromones and animal behavior communication by smell and taste. Cambridge: Cambridge University Press; 2003.

2. Saetre GP, Moum T, Bures S, Kral M, Adamjan M, Moreno J. A sexually selected character displacement in flycatchers reinforces premating isolation. Nature. 1997;387(6633):589-92.

3. Maan ME, Seehausen O. Ecology, sexual selection and speciation. Ecol Lett. 2011;14(6):591-602.

4. Baker TC. Mechanism for saltational shifts in pheromone communication systems. Proc Natl Acad Sci U S A. 2002;99(21):13368-70.

5. Symonds MRE, Elgar MA. The evolution of pheromone diversity. Trends Ecol Evol. 2008;23(4):220-8.

6. Carde RT, Carde AM, Hill AS, Roelofs WL. Sex pheromone specificity as a reproductive isolating mechanism among sibling species Archips argyrospilus and A. mortuanus and other sympatric tortricine moths (Lepidoptera: Tortricidae). J Chem Ecol. 1977:3(1):71-84.

7. Coyne JA, Orr HA. Patterns of speciation in Drosophila. Evolution. 1989; 43(2):362-81.

8. Coyne JA, Orr HA. "Patterns of speciation in Drosophila" revisited. Evolution. 1997:51(1):295-303.

9. Dani FR, Jones GR, Corsi S, Beard R, Pradella D, Turillazzi S. Nestmate recognition cues in the honey bee: differential importance of cuticular alkanes and alkenes. Chem Senses. 2005;30(6):477-89.

10. Chapman AD. Numbers of living species in Australia and the world. 2 nd ed. Canberra: Australian Biological Resources Study; 2009.

11. Greenfield MD. Signalers and receivers: mechanisms and evolution of arthropod communication. New York, USA: Oxford University Press; 2002.

12. Missbach C, Dweck HK, Vogel H, Vilcinskas A, Stensmyr MC, Hansson BS, Grosse-Wilde E. Evolution of insect olfactory receptors. elife. 2014:3:e02115.

13. Antony C, Jallon JM. The chemical basis for sex recognition in Drosophila melanogaster. J Insect Physiol. 1982;28(10):873-80.

14. Cobb M, Jallon JM. Pheromones, mate recognition and courtship stimulation in the Drosophila melanogaster species subgroup. Anim Behav. 1990;39:1058-67.

15. Simmons LW, Alcock J, Reeder A. The role of cuticular hydrocarbons in male attraction and repulsion by female Dawson's burrowing bee, Amegilla dawsoni. Anim Behav 2003; 66:677-685.

16. Howard RW, Blomquist GJ. Ecological, behavioral, and biochemical aspects of insect hydrocarbons. Annu Rev Entomol. 2005;50:371-93.

17. Singer TL. Roles of hydrocarbons in the recognition systems of insects. Am Zool. 1998;38(2):394-405

18. Howard RW, Jackson LL, Banse H, Blows MW. Cuticular hydrocarbons of Drosophila birchii and D. serrata: identification and role in mate choice in D. serrata. J Chem Ecol. 2003:29(4):961-76.

19. Tanigaki T, Yamaoka R, Sota T. The role of cuticular hydrocarbons in mating and conspecific recognition in the closely related longicorn beetles Pidonia grallatrix and P. takechii. Zool Sci. 2007;24(1):39-45.

20. South A, Levan K, Leombruni L, Orians CM, Lewis SM. Examining the role of cuticular hydrocarbons in firefly species recognition. Ethology. 2008;114(9):916-24

21. Xue H-J, Wei J-N, Magalhaes S, Zhang B, Song K-Q, Liu J, Li W-Z, Yang X-K. Contact pheromones of 2 sympatric beetles are modified by the host plant and affect mate choice. Behav Ecol. 2016;27(3):895-902.

22. Geiselhardt S, Otte T, Hilker M. Looking for a similar partner: host plants shape mating preferences of herbivorous insects by altering their contact pheromones. Ecol Lett. 2012;15(9):971-7.

23. Peterson MA, Dobler S, Larson EL, Juarez D, Schlarbaum T, Monsen KJ, Francke W. Profiles of cuticular hydrocarbons mediate male mate choice and sexual isolation between hybridising Chrysochus (Coleoptera Chrysomelidae). Chemoecology. 2007;17(2):87-96.

24. Hay-Roe MM, Lamas G, Nation JL. Pre- and postzygotic isolation and Haldane rule effects in reciprocal crosses of Danaus erippus and Danaus plexippus (Lepidoptera: Danainae), supported by differentiation of cuticular hydrocarbons, establish their status as separate species. Biol J Linn Soc. 2007:91(3):445-53.

25. Howard RW. Comparative-analysis of cuticular hydrocarbons from the ectoparasitoids Cephalonomia waterstoni and Laelius utilis (Hymenoptera, Bethylidae) and their respective hosts, Cryptolestes ferrugineus (Coleoptera, 
Cucujidae) and Trogoderma variabile (Coleoptera, Dermestidae). Ann Entomol Soc Am. 1992:85:317-25.

26. Syvertsen TC, Jackson LL, Blomquist C, Vinson SB. Alkadienes mediating courtship in the parasitoid Cardiochiles nigriceps (Hymenoptera: Braconidae). J Chem Ecol. 1995;21(12):1971-89.

27. Dembeck LM, Boroczky K, Huang W, Schal C, Anholt RRH, Mackay TFC. Genetic architecture of natural variation in cuticular hydrocarbon composition in Drosophila melanogaster. elife. 2015;4:4.

28. Chenoweth SF, Blows MW. Contrasting mutual sexual selection on homologous signal traits in Drosophila serrata. Am Nat. 2005;165(2):281-9.

29. Yew JY, Dreisewerd K, Luftmann H, Muthing J, Pohlentz G, Kravitz EA. A new male sex pheromone and novel cuticular cues for chemical communication in Drosophila. Curr Biol. 2009;19(15):1245-54

30. Jallon JM, David JR. Variations in cuticular hydrocarbons among the 8 species of the Drosophila melanogaster subgroup. Evolution. 1987:41 (2):294-302.

31. Jallon JM. A few chemical words exchanged by Drosophila during courtship and mating. Behav Genet. 1984;14(5):441-78.

32. Coyne JA, Crittenden AP, Mah K Genetics of a pheromonal difference contributing to reproductive isolation in Drosophila. Science. 1994;265(5177):1461-4.

33. Carracedo MC, Asenjo A, Casares P. Genetics of Drosophila simulans male mating discrimination in crosses with D. melanogaster. Heredity. 2003;91(3):202-7.

34. Coyne JA, Charlesworth B. Genetics of a pheromonal difference affecting sexual isolation between Drosophila mauritiana and D. sechellia. Genetics. 1997;145(4):1015-30.

35. Ishii K, Hirai Y, Katagiri C, Kimura MT. Sexual isolation and cuticular hydrocarbons in Drosophila elegans. Heredity. 2001;87:392-9.

36. Mas $F$, Jallon JM. Sexual isolation and cuticular hydrocarbon differences between Drosophila santomea and Drosophila yakuba. J Chem Ecol. 2005; 31(11):2747-52.

37. Higgie M, Blows MW. Are traits that experience reinforcement also under sexual selection? Am Nat. 2007;170(3):409-20.

38. Mallet J. What does Drosophila tell us about speciation? Trends Ecol Evol. 2006;21(7):386-93.

39. Werren JH, Loehlin DW. The parasitoid wasp Nasonia: an emerging model system with haploid male genetics. Cold Spring Harb Protoc. 2009;

40. Werren JH, Richards S, Desjardins CA, Niehuis O, Gadau J, Colbourne JK. The Nasonia genome working group. Functional and evolutionary insights from the genomes of three parasitoid Nasonia species. Science. 2010;327(5963):343-8.

41. Niehuis O, Buellesbach J, Judson AK, Schmitt T, Gadau J. Genetics of cuticular hydrocarbon differences between males of the parasitoid wasps Nasonia giraulti and Nasonia vitripennis. Heredity. 2011;107(1):61-70.

42. Steiner S, Hermann N, Ruther J. Characterization of a female-produced courtship pheromone in the parasitoid Nasonia vitripennis. J Chem Ecol. 2006;32:1687-702.

43. Buellesbach J, Gadau J, Beukeboom LW, Echinger F, Raychoudhury R, Werren JH, Schmitt T. Cuticular hydrocarbon divergence in the jewel wasp Nasonia: evolutionary shifts in chemical communication channels? J Evol Biol. 2013;26(11):2467-78.

44. Mair MM, Kmezic V, Huber S, Pannebakker BA, Ruther J. The chemical basis of mate recognition in two parasitoid wasp species of the genus Nasonia. Entomol Exp Appl. 2017;164(1):1-15

45. Campbell B, Heraty J, Rasplus J-Y, Chan K, Steffen-Campbell J, Babock C. Molecular systematics of the Chalcidoidea using 28S-D2 rDNA. In: Austin $A D$, Dowton $M$, editors. Hymenoptera: evolution, biodiversity and biological control. Clayton South: CISRO Publishing; 2000.

46. Floate KD. Field trials of Trichomalopsis sarcophagae (Hymenoptera : Pteromalidae) in cattle feedlots: a potential biocontrol agent of filth flies (Diptera : Muscidae). Can Entomol. 2003;135(4):599-608.

47. Gibson GAP, Floate K. Species of Trichomalopsis (Hymenoptera Pteromalidae) associated with filth flies (Diptera : Muscidae) in North America. Can Entomol. 2001;133(1):49-85.

48. Kogan $\mathrm{M}$, Legner E. A biosystematic revision of the genus Muscidifurax (Hymenoptera: Pteromalidae) with descriptions of four new species. The Canadian Entomologist. 1970;102:1268-90

49. Gottlieb Y, Zchori-Fein E. Irreversible thelytokous reproduction in Muscidifurax uniraptor. Entomol Exp Appl. 2001;100(3):271-8.

50. Legner EF. Natural and induced sex-ratio changes in populations of thelytokous Muscidifurax uniraptor (Hymenoptera, Pteromalidae). Ann Entomol Soc Am. 1985;78(3):398-402.

51. Gates M. CD-ROM review: interactive catalogue of world Chalcidoidea 2001 (2nd edition). J N Y Entomol Soc. 2003;111(1):61-3.
52. Machtinger ET, Geden CJ, Kaufman PE, House AM. Use of pupal parasitoids as biological control agents of filth flies on equine facilities. Journal of Integrated Pest Management. 2015;6(1):1-10. https://doi.org/10.1093/jipm/ pmv015.

53. Carlson DA, Geden CJ, Bernier UR. Identification of pupal exuviae of Nasonia vitripennis and Muscidifurax raptorellus parasitoids using cuticular hydrocarbons. Biol Control. 1999;15:97-105.

54. Floate K, Khan B, Gibson G. Hymenopterous parasitoids of filth fly (Diptera : Muscidae) pupae in cattle feedlots. Can Entomol. 1999;131(3):347-62.

55. Smadja C, Butlin RK. On the scent of speciation: the chemosensory system and its role in premating isolation. Heredity. 2009;102(1):77-97.

56. Schneiderman HA, Horwitz J. The induction and termination of facultative diapause in the chalcid wasps Mormoniella vitripennis (Walker) and Tritneptis Klugii (Ratzeburg). J Exp Biol. 1958;35(3):520-51.

57. Ruther J, Homann M, Steidle JLM. Female-derived sex pheromone mediates courtship behaviour in the parasitoid Lariophagus distinguendus. Entomol Exp Appl. 2000;96(3):265-74

58. van den Assem J, Vernel C. Courtship behaviour of Nasonia vitripennis (Hym.: Pteromalidae): observations and experiments on male readiness to assume copulatory behaviour. Behaviour. 1979;68:118-35.

59. van den Assem J, Werren JH. A comparison of the courtship and mating behavior of three species of Nasonia (Hymenoptera: Pteromalidae). J Insect Behav. 1994;7(1):53-66.

60. Barrass R. The courtship behaviour of Mormoniella vitripennis walk. (Hymenoptera, Pteromalidae). Behaviour. 1960;15:185-209.

61. van den Assem J. Male courtship behavior female receptivity signal and size differences between the sexes in Pteromalinae (Hymenoptera, Chalcidoidea, Pteromalidae) and comparative notes on other chalcidoids. Neth J Zool. 1976;26(4):535-48.

62. van den Assem J. Male courtship patterns and female receptivity signal of Pteromalinae (Hym., Pteromalidae), with a consideration of some evolutionary trends and a comment on the taxonomic position of Pachycrepoideus Vindemiae. Neth J Zool. 1973;24(3):253-78.

63. Giesbers M, Gerritsma S, Buellesbach J, Diao W, Pannebakker BA, van de Zande L, Schmitt T, Beukeboom LW. Prezygotic isolation in the parasitoid wasp genus Nasonia. In: Michalak P, editor. Speciation: natural processes, genetics and biodiversity. Hauppauge NY, USA: Nova Science Publishers; 2013.

64. Hadley NF. Cuticular lipids of terrestrial plants and arthropods - a comparison of their structure, composition, and waterproofing function. Biol Rev Camb Philos Soc. 1981;56(1):23-47.

65. Gibbs AG. Water-proofing properties of cuticular lipids. Am Zool. 1998;38(3): 471-82.

66. Benjamini Y, Hochberg Y. Controlling the false discovery rate: a practical and powerful approach to multiple testing. J Roy Stat Soc Ser B (Stat Method). 1995:57(1):289-300.

67. R Development Core Team. R: a language and environment for statistical computing. Vienna, Austria: R foundation for statistical computing; 2010. http://www.R-project.org

68. Carlson DA, Bernier UR, Sutton BD. Elution patterns from capillary GC for methyl-branched alkanes. J Chem Ecol. 1998;24(11):1845-65.

69. Venables WN, Ripley BD. Modern applied statistics with S. Fourth edn. New York: Springer; 2002.

70. Ligges U, Maechler M. Scatterplot3d - An R package for visualizing multivariate data. J Stat Softw. 2003:8(11):1-20.

71. Darling DC, Werren JH. Biosystematics of Nasonia (Hymenoptera: Pteromalidae): two new species reared from birds' nests in North America. Ann Entomol Soc Am. 1990;83:352-70.

72. Raychoudhury R, Desjardins CA, Buellesbach J, Loehlin DW, Grillenberger BK, Beukeboom LW, Schmitt T, Werren JH. Behavioral and genetic characteristics of a new species of Nasonia. Heredity. 2010;104(3):278-88.

73. Buellesbach J, Greim C, Schmitt T. Asymmetric interspecific mating behavior reflects incomplete prezygotic isolation in the jewel wasp genus Nasonia. Ethology. 2014;120(8):834-43

74. Johansson BG, Jones TM. The role of chemical communication in mate choice. Biol Rev. 2007:82(2):265-89.

75. Coyne JA, Orr HA. Speciation. Sunderland, MA: Sinauer Associates; 2004

76. Breeuwer JAJ, Werren JH. Microorganisms associated with chromosome destruction and reproductive isolation between two insect species. Nature. 1990;346:558-60.

77. Bordenstein SR, O'Hara FP, Werren JH. Wolbachia induced incompatibility precedes other hybrid incompatibilities in Nasonia. Nature. 2001;409:707-10. 
78. Bordenstein SR, Werren JH. Effects of a and B Wolbachia and host genotype on interspecies cytoplasmic incompatibility in Nasonia. Genetics. 1998; 148(4):1833-44.

79. Buckley SH, Tregenza T, Butlin RK. Speciation and signal trait genetics. Trends Ecol Evol. 1997;12(8):299-301.

80. Chung H, Carroll SB. Wax, sex and the origin of species: dual roles of insect cuticular hydrocarbons in adaptation and mating. BioEssays. 2015;37(7):822-30.

81. van den Assem J, Gijswijt MJ, Nubel BK. Observations on courtship and mating strategies in a few species of parasitic wasps (Chalcidoidea). Neth $J$ Zool. 1980;30(2):208-27.

82. van den Assem J. Mating behaviour in parasitic wasps. In: Waage JK, Greathead D, editors. Insect parasitoids. London: Academic Press; 1986. p. 137-67.

83. Ma WJ, Pannebakker BA, Beukeboom LW, Schwander T, van de Zande L. Genetics of decayed sexual traits in a parasitoid wasp with endosymbiontinduced asexuality. Heredity. 2014:113(5):424-31.

84. Zwier MV, Verhulst EC, Zwahlen RD, Beukeboom LW, van de Zande L. DNA methylation plays a crucial role during early Nasonia development. Insect Mol Biol. 2012;21(1):129-38

85. Blows MW, Allan RA. Levels of mate recognition within and between two Drosophila species and their hybrids. Am Nat. 1998;152(6):826-37.

86. Coyne JA. Genetics of differences in pheromonal hydrocarbons between Drosophila melanogaster and D. simulans. Genetics. 1996;143(1):353-64.

87. Kondrashov AS, Shpak M. On the origin of species by means of assortative mating. Proc R Soc Lond Ser B Biol Sci. 1998;265(1412):2273-8.

Ready to submit your research? Choose BMC and benefit from:

- fast, convenient online submission

- thorough peer review by experienced researchers in your field

- rapid publication on acceptance

- support for research data, including large and complex data types

- gold Open Access which fosters wider collaboration and increased citations

- maximum visibility for your research: over $100 \mathrm{M}$ website views per year

At BMC, research is always in progress.

Learn more biomedcentral.com/submissions 